\title{
Does pH of tyrode solution modify glucose and electrolyte jejunal absorption in rats?
}

\author{
Elizabeth Lage Borges*, Marcelo de Pinho Viana
}

Departamento de Fisiologia e Biofísica, Instituto de Ciências Biológicas, Universidade Federal de Minas Gerais, Belo Horizonte, Brazil; *Corresponding Author: borgesel@icb.ufmg.br

Received 14 December 2011; revised 29 January 2012; accepted 10 February 2012

\begin{abstract}
Studies have shown that glucose is able to decrease the $\mathrm{pH}$ of the surface epithelium jejunal preparations when added in vitro and the existence of a high concentration of protons in the immediate area of the mucosa could be of considerable significance for absorption of electrolytes. The aim of this study is to assess whether the change in $\mathrm{pH}$ of Tyrode (solution used for perfusion of the jejunum) interferes with the absorption of glucose and electrolytes. Male Wistar rats weighing 200 to $220 \mathrm{~g}(\mathrm{n}=6)$ were utilized. Jejunal absorption of glucose and electrolytes was investigated in rats. A Tyrode solution containing twice glucose, sodium and potassium concentration ( $\mathrm{pH} 7.0,7.4,8.0$ and 8.5 ) was infused through the jejunal loops during $\mathbf{4 0}$ minutes. The glucose absorption was not significantly affected by Tyrode. However, there was significantly decrease in sodium absorption at pH 7.0 and $8.5(41.13 \pm 2.79$ and $41.37 \pm 1.71$, respectively, $\mathrm{P}<0.05)$ when compared with the uptake at pH 7.4 and $8.0(61.06 \pm 6.50$ and $56.28 \pm$ 7.03 , respectively, $P<0.05)$. Moreover, potassium absorption increased at pH $8.0(1.04 \pm 0.07)$ when compared with the uptake at pH $7.0(0.59 \pm$ $0.04), 7.4(0.78 \pm 0.08)$ and $8.5(0.54 \pm 0.05)(P<$ 0.05). These data indicate that the $\mathrm{pH}$ of Tyrode has no influence on glucose absorption. However, the major potassium uptake occurs at $\mathrm{pH}$ 8.0 , while the absorption of sodium is impaired at $\mathrm{pH} 7.0$ and 8.5 .
\end{abstract}

Keywords: Absorption; pH; Glucose; Sodium; Potassium; Jejunum

\section{INTRODUCTION}

Studies have shown that glucose is able to decrease the $\mathrm{pH}$ of the surface epithelium of duodenal and jejunal preparations when added in vitro [1,2], although the aci- dification is not caused by glucose transport alone [3]. This effect is reproduced when the substrate is administered in vivo [1]. It is plausible that the generation of protons, which are secreted into this region, is closely related to the intracellular metabolism of glucose and lactate production. The existence of a high concentration of protons in the immediate surface of the mucosa could be of considerable significance for the absorption of electrolytes [1].

Recent studies suggest that changes in extracellular $\mathrm{pH}$ affect the ionization state of membrane proteins includeing transporters and ion channels with specific functions in transporting epithelia [4]. The surface $\mathrm{pH}$ of rat intestine had been measured in vivo, confirming the phenomenon of acidification in the jejunum followed by an alkalinization process in the ileum [5]. However, no difference in the $\mathrm{pH}$ of the intestinal surface was detected when the bicarbonate buffer was used or when glucose was included in the buffer. Several factors can affect the intestinal absorption of glucose, electrolytes and water, such as nutritional deficiency [6] or absorption modulation by hormones [7] and peptides [8-12] via the autonomic nervous system. However, the different experimental models used in absorption studies have employed different physiological solutions for infusion, such as Ringer's solution [13], Krebs' solution [14], Tyrode solution $[8-11,14,15]$ and phosphate buffer $[16,17]$, with a broad range of variation in the $\mathrm{pH}$ of these solutions $(\mathrm{pH}$ 7 to $\mathrm{pH} 8$ ).

The purpose of the present study was to determine whether a change in the $\mathrm{pH}$ of Tyrode solution (used for jejunal perfusion) affects the absorption of glucose and electrolytes. These significant new data concerning the dependence of glucose or electrolytes absorption on the $\mathrm{pH}$ of Tyrode solution may help to improve methodological approach in future studies of intestinal transport.

\section{MATERIAL AND METHODS}

\subsection{Animals}

Adult male Wistar rats weighing 200 to 220 g were 
housed under standard laboratory conditions of a 12:12-h light/dark cycle and controlled temperature $\left(23^{\circ} \mathrm{C} \pm 3^{\circ} \mathrm{C}\right)$. The animals were fasted for $12 \mathrm{~h}$ prior to the experimenttal procedures, but water was offered ad libitum. All experiments complied with the International Principles of Animal Care and the study received approval from the local Ethics Committee on Animal Experimentation (CETEA/UFMG process $n^{\circ}$ 230/2010).

\subsection{General Procedures}

The rats were anesthetized with thiopental (Cristália, Brazil) (40 mg/kg i.p.). Following the procedures of median xypho-pubic laparotomy, a 20-cm segment of jejunum after the duodenojejunal ligament was isolated, preserving the nerves and the vascular pedicle. Two cannulae were then inserted into the extremities of the jejunal loop-one for perfusion and the other for fluid drainage. The abdominal wall was then closed in order to prevent tissue dehydration. Both cannulae were exteriorized through the extremities of the abdominal suture. Tyrode solution (137 mM NaCl, $2.7 \mathrm{mM} \mathrm{KCl,} 1.36 \mathrm{mM} \mathrm{CaCl}_{2}, 0.49$ $\mathrm{mM} \mathrm{MgCl} 2,11.9 \mathrm{mM} \mathrm{NaHCO}$, and $5 \mathrm{mM}$ D-glucose) was maintained in a bottle connected to the catheter infusion pump at $37^{\circ} \mathrm{C}$ in a bath. Tyrode solution $\mathrm{pH} 8.0$ (buffered by $\mathrm{HCO}_{3}^{-}$) was perfused at a rate of 0.5 $\mathrm{ml} \cdot \mathrm{msin}^{-1}$ for $15 \mathrm{~min}$ in order to equilibrate the fluids to reach steady state within the jejunal lumen [8].

The rats were divided into four groups: Group $1(n=6)$ received Tyrode solution $\mathrm{pH} 7.0$; Group $2(\mathrm{n}=6)$ received Tyrode solution $\mathrm{pH} 7.4$; Group $3(\mathrm{n}=6)$ received Tyrode solution $\mathrm{pH}$ 8.0; Group $4(\mathrm{n}=6)$ received Tyrode solution $\mathrm{pH}$ 8.5 The rats in all four groups were submitted to the infusion of a Tyrode solution containing twice the usual concentrations of glucose, sodium and potassium during the 40-min experiment, under the same conditions described above for Tyrode solution. The effluents were collected separately in test tubes at 10 -min intervals and maintained in ice, then stored in a freezer at $-20^{\circ} \mathrm{C}$ until the biochemical analysis.

\subsection{Biochemical Determinations}

The glucose concentration of the effluent was determined by an enzymatic method based on glucose oxidase (Glucose PAP Liquiform, Labtest, Brazil), estimated from a standard glucose concentration curve. Effluent potassium and sodium ion concentrations were measured by flame photometry. The results were expressed by the difference between influx and efflux.

\subsection{Statistical Analysis}

Split-plot analysis of variance (ANOVA), followed by the Student-Newman-Keuls method, was used for the statistical analysis, with the level of significance set at
$5 \%(\mathrm{P}<0.05)$

\section{RESULTS AND DISCUSSION}

Figure 1 shows the effect of Tyrode $\mathrm{pH}$ on jejunal glucose absorption. There were no differences in glucose absorption among the four groups.

Figure 2 displays the effect of Tyrode $\mathrm{pH}$ on jejunal sodium absorption. There was a significant decrease in sodium absorption at $\mathrm{pH} 7.0$ and 8.5 when compared with uptake at $\mathrm{pH} 7.4$ and $8.0(\mathrm{P}<0.05)$. Tyrode $\mathrm{pH} 7.4$ increased sodium absorption. Moreover, no statistically significant difference was found between Tyrode $\mathrm{pH} 8.0$ and Tyrode $\mathrm{pH}$ 7.4.

A significant decrease in sodium absorption at $\mathrm{pH} 7.0$ and 8.5 as compared with uptake at $\mathrm{pH} 7.4$ and 8.0 probably is a result of adverse conditions of extreme acidosis or alkalosis. However, the physiological $\mathrm{pH}$ favored sodium absorption that was not different from $\mathrm{pH}$ 8.0.

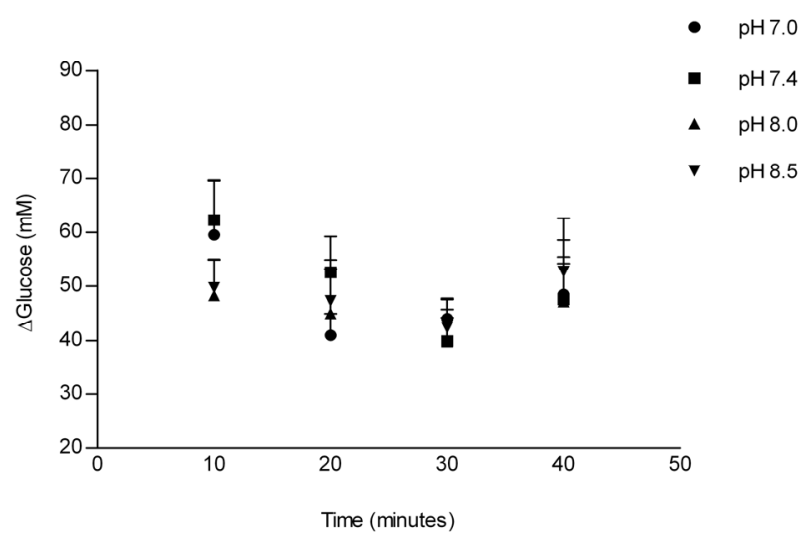

(a)

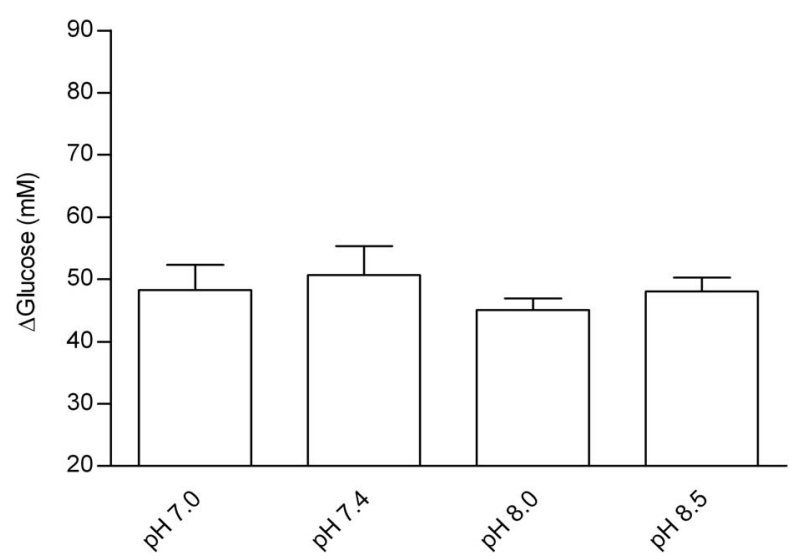

(b)

Figure 1. Effects of Tyrode $\mathrm{pH}$ on jejunal glucose absorption; (a) represents the time course of the effect of Tyrode $\mathrm{pH}$; and (b) represents mean \pm SEM for all time points of each $\mathrm{pH}$. The results were expressed by the difference between influx and efflux. There was no difference in glucose absorption among the groups perfused with Tyrode solution at different $\mathrm{pH}$ values. 


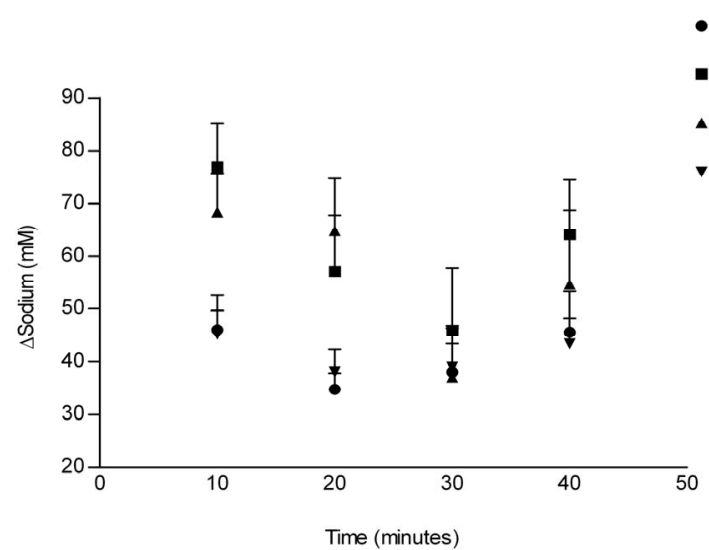

(a)

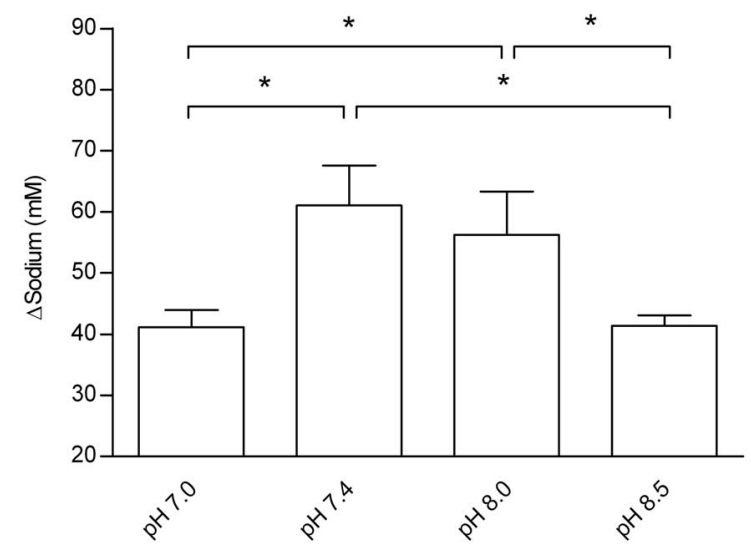

(b)

Figure 2. Effects of Tyrode $\mathrm{pH}$ on jejunal sodium absorption; (a) represents the time course of the effect of Tyrode $\mathrm{pH}$; (b) represents mean \pm SEM for all time points of each $\mathrm{pH}$. The results were expressed by the difference between influx and efflux. Sodium absorption in the group perfused with Tyrode solution pH 7.4 was higher that of the other groups $\left({ }^{*} \mathrm{P}<0.05\right)$. Sodium absorption increased at $\mathrm{pH} 8.0$ when compared with Tyrode $\mathrm{pH} 8.5$ and $\mathrm{pH} 7.0$ ( $\left.^{*} \mathrm{P}<0.05\right)$. ${ }^{*}$ Denotes significant $(\mathrm{P}<$ 0.05 ) difference in relation to the other groups.

Figure 3 shows the effect of Tyrode $\mathrm{pH}$ on jejunal potassium absorption. Absorption in the group that received Tyrode solution $\mathrm{pH} 8.0$ was greater than that in the groups that received solutions with $\mathrm{pH} 8.5$ and $7.4(\mathrm{P}<0.05)$. It seems that the absorption of potassium is strongly dependent on $\mathrm{pH}$. Moreover, there was a decrease in potassium absorption at $\mathrm{pH} 7.0$, indicating that a high concentration of protons in the Tyrode solution could be of considerable significance for impair potassium jejunal absorption. This impairment maybe due to conformational changes in potassium channels since the activation of these channels occurs in extracellular alkalinization [4,18-20].

The novel findings of the present study are that the $\mathrm{pH}$ of Tyrode solution in jejunal perfusion did not affect glucose absorption, whereas greater potassium absorption occurred with Tyrode $\mathrm{pH} 8.0$ and greater sodium absorption occurred with Tyrode $\mathrm{pH}$ 7.4.

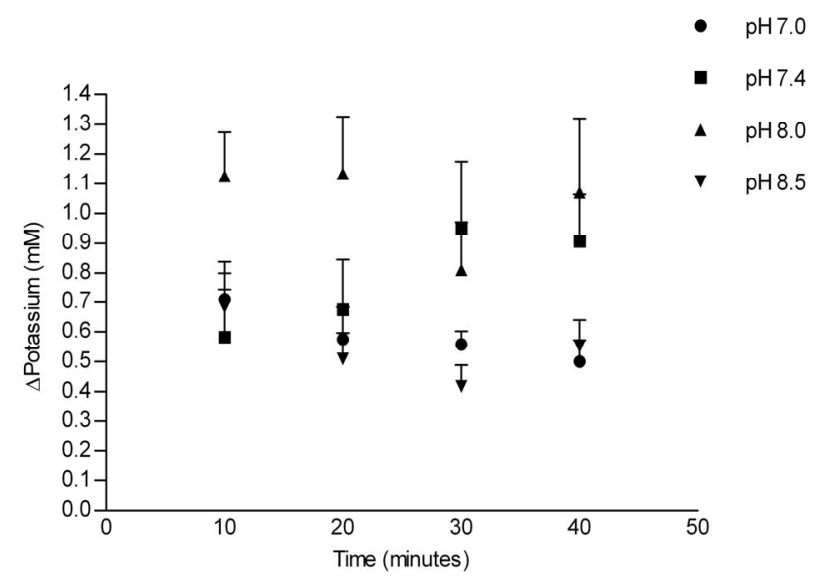

(a)

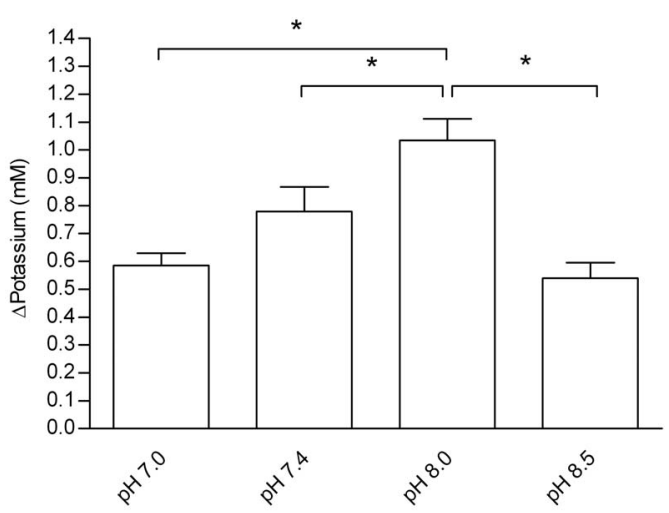

(b)

Figure 3. Effects of Tyrode $\mathrm{pH}$ on jejunal potassium absorption; (a) represents the time course of the effect o Tyrode $\mathrm{pH}$; (b) represents mean \pm SEM for all time points of each $\mathrm{pH}$. The results were expressed by the difference between influx and efflux. Potassium absorption in the group perfused with Tyrode solution $\mathrm{pH} 8.0$ increased when compared with uptake at $\mathrm{pH}$ 7.0, 7.4 and $8.5\left(^{*} \mathrm{P}<0.05\right)$. ${ }^{*}$ Denotes significant $(\mathrm{P}<0.05)$ difference in relation to the other groups.

The transport of glucose is mainly affected by the amount of sodium in the intestinal lumen. A high concentration of sodium on the mucosal surface facilitates the glucose influx into the epithelial cells. Glucose and sodium share the same co-transporter 1 (SGLT1) in the brush border membrane. Thus, glucose transport is an example of secondary active transport, provided indirectly by the active transport of sodium out of the cell, which maintains the concentration gradient across the luminal border of the cell. Glucose then passively passes from the enterocytes to the circulation through glucose transporter 2 (GLUT-2) in the basolateral membrane [21]. The $\mathrm{Na}^{+} / \mathrm{H}^{+}$exchange which occurs by NHE1 found in basolateral membrane, NHE2 and NHE3 both at the brush border membrane of the intestinal epithelium [22-25] and $\mathrm{Na}^{+}$absorption through the $\mathrm{Na}^{+} / \mathrm{Cl}^{-}$co-transporter [22] are alternative sodium absorption pathways. It could be suggested that these alternative pathways to sodium uptake were impaired 
by Tyrode $\mathrm{pH}$, which would explain the dissociation of glucose and sodium uptakes regarding Tyrode $\mathrm{pH}$.

In addition, acidification ( $\mathrm{pH}$ 7.0) or alkalinization (pH 8.5) produced by changes in the $\mathrm{pH}$ of Tyrode solution impaired sodium absorption. Based on the absorption studies, Tyrode $\mathrm{pH} 7.4$ is the best choice for improving sodium absorption, followed by Tyrode $\mathrm{pH}$ 8.0.

Acidification produced by Tyrode $\mathrm{pH} 7.0$ impaired potassium absorption. Moreover, the physiological condition (Tyrode $\mathrm{pH}$ 7.4) or alkalinization (Tyrode $\mathrm{pH}$ 8.5) reduced potassium absorption when compared to Tyrode $\mathrm{pH}$ 8.0. The mechanism proposed for potassium absorption in the small intestine is passive diffusion through either an intercellular or paracellular pathway, favoring a potential transmembrane gradient due to water absorption secondary to the active transport of sodium or other solutes that concentrate potassium within the intestinal lumen [26]. It has also been suggested that potassium may be absorbed by an active transport mechanism operating through the cellular pathway [26]. Interestingly, potassium is the most abundant ion in intracellular fluid and plays an important role in acid-base homeostasis. Moreover, the results of the present study suggest that potassium absorption mechanisms seem to be dependent on $\mathrm{pH}$. The active transport mechanism is likely to be influenced by $\mathrm{pH}$.

\section{CONCLUSION}

In conclusion, Tyrode $\mathrm{pH}$ did not affect jejunal glucose absorption, but did affect jejunal electrolyte absorption. The optimal value for jejunal potassium absorption was $\mathrm{pH} 8.0$ and the optimal value for sodium absorption was 7.4, which did not differ significantly from the result obtained with $\mathrm{pH}$ 8.0. These results suggest that a Tyrode solution with $\mathrm{pH} 8.0$ is the best choice in studies involving jejunal perfusion and glucose and electrolyte absorption.

\section{REFERENCES}

[1] Daniel, H. and Gertrud, R. (1986) Effect of metabolizable sugars on the mucosal surface $\mathrm{pH}$ of rat intestine. Journal of Nutrition, 116, 768-777.

[2] Lucas, M.L. Lei, F.H. and Blair, J.A. (1980) The influence of buffer $\mathrm{pH}$, glucose and sodium ion concentration on the acid microclimate in rat proximal jejunum in vitro. Pflüegers Archives, 385, 137-142. doi:10.1007/BF00588693

[3] Blair, J.A., Lucas, M.L. and Matty, A.J. (1975) Acidification in the rat proximal jejunum. Journal of Physiology, 245, 333-350.

[4] Sandoval, M., Burgos, J., Sepúlveda, F.V. and Pablo, L. (2011) Extracellular pH in restricted domains as a gating signal for ion channels involvement in transepithelial trans- port. Biological \& Pharmaceutical Bulletin, 34, 803-809. doi:10.1248/bpb.34.803

[5] Lucas, M. (1983) Determination of acid surface $\mathrm{pH}$ in vivo in rat proximal jejunum. Gut, 24, 734-739. doi:10.1136/gut.24.8.734

[6] Wayhs, M.L.C., Morais, M.B., Machado, U.F., Nassar, S.M., Fagundes Neto, U. and Amâncio, O.M.A. (2011) Transepithelial transport of glucose and mRNA of glucose transporters in the small intestine of rats with irondeficiency anemia. Nutrition, 27, 111-115. doi:10.1016/j.nut.2010.07.002

[7] Hubel, K.A. (1976) Intestinal ion transport: Effect of norepinephrine, pilocarpine, and atropine. The American Journal of Physiology, 231, 252-257.

[8] Borges, E.L., Machado, A.D.C.V., Haibara, A.S. and Petroianu, A. (2003) Effects of vasoactive intestinal polypeptide microinjected into the nucleus tractus solitarius on jejunal glucose absorption in rats. Autonomic Neuroscience: Basic and Clinical, 107, 111-113.

doi:10.1016/S1566-0702(03)00074-2

[9] Machado, D.C.V., Haibara, A.S., Petroianu, A. and Borges, E.L. (2005) Effects of vasoactive intestinal polypeptide microinjected into the nucleus tractus solitarius on jejunal electrolytes absorption in rats. Neuropeptides, 39, 15-19. doi:10.1016/j.npep.2004.10.001

[10] Nogueira, M.C., Haibara, A.S. and Borges, E.L. (2010) Effect of L-NAME microinjected into the nucleus tractus solitarius on jejunal glucose and electrolyte absorption in anesthetized rats. Brain Research, 1359, 107-115. doi:10.1016/j.brainres.2010.08.079

[11] Vaz, G.C., Xavier, C.H., Coimbra, C.C., Fontes, M.A.P. and Borges, E.L. (2011) Increased Jejunal Absorption of Glucose in Rats Submitted to Blockade of GABAA Receptors in the Hypothalamic Paraventricular Nucleus. The Open Neuroendocrinology Journal, 4, 120-126. doi:10.2174/1876528901104010120

[12] Cox, H.M. (2007) Neuropeptide Y receptors; antisecretory control of intestinal epithelial function. Autonomic Neuroscience, 133, 76-85.

doi:10.1016/j.autneu.2006.10.005

[13] Tanaka, K., Morita, H., Suwaki, H., Hosokawa, K. and Hosomi, H. (1994) Effects of microinjection of kainic acid into the nucleus tractus solitarius on fluid and $\mathrm{NaCl}$ absorption across the jejunum. Journal of the Autonomic Nervous System, 48, 97-104. doi:10.1016/0165-1838(94)90025-6

[14] Kim, M.H., Hardin, J.A. and Gall, D.G. (1996) The role of nitric oxide in the regulation of macromolecular transport in rat jejunum. Journal of Physiology, 490, 243-248.

[15] Schirgi-Degen, A. and Beubler, E. (1995) Significance of nitric oxide in the stimulation of intestinal fluid absorption in the rat jejunum in vivo. British Journal of Pharmacology, 114, 13-18.

[16] Fetih, G., Habib, F., Katsumi, H., Okada, N., Fujita, T., Attia, M. and Yamamoto, A. (2006) Excellent absorption enhancing characteristics of NO donors for improving the intestinal absorption of poorly absorbable compound compared with conventional absorption enhancers. Drug Metabolism and Pharmacokinetics, 21, 222-229. 
doi:10.2133/dmpk.21.222

[17] Varma, M.V.S. and Panchagnula, R. (2005). pH-Dependent functional activity of P-glycoprotein in limiting intestinal absorption of protic drugs: Kinetic analysis of quinidine efflux in situ. Journal of Pharmaceutical Sciences, 94, 2632-2643. doi:10.1002/jps.20489

[18] Goldstein, S.A., Bockenhauer, D., O’Kelly, I. and Zilberberg, N. (2001) Potassium leak channels and the KCNK family of two-P-domain subunits. Nature Reviews Neuroscience, 2, 175-184. doi:10.1038/35058574

[19] Lotshaw, D.P. (2007) Biophysical, pharmacological, and functional characteristics of cloned and native mammalian two-pore domain $\mathrm{K}^{+}$channels. Cell Biochemistry and Biophysics, 47, 209-256. doi:10.1007/s12013-007-0007-8

[20] Zúñiga, L., Márquez, V., González-Nilo, F.D., Chipot, C., Cid, L.P., Sepúlveda, F.V. and Niemeyer, M.I. (2011) Gating of a $\mathrm{pH}$-sensitive $\mathrm{K}_{2 \mathrm{p}}$ potassium channel by an electrostatic effect of basic sensor residues on the selectivity filter. PLoS One, 6, e16141. doi:10.1371/journal.pone.0016141

[21] Zahedi, A.S.L. and Alipour, M. (2007) The effects of insulin on glucose and fluid transport in the isolated small in- testine of normal rats. Life Sciences, 81, 26-30. doi:10.1016/j.lfs.2007.04.021

[22] Kato, A. and Romero, M.F. (2011) Regulation of electroneutral $\mathrm{NaCl}$ absorption by small intestine. Annual Review of Physiology, 73, 261-281. doi:10.1146/annurev-physiol-012110-142244

[23] Zachos, N.C., Tse, M. and Donowitz M. (2005) Molecular physiology of intestinal $\mathrm{Na}^{+} / \mathrm{H}^{+}$exchange. Annual Review of Physiology, 67, 411-443. doi:10.1146/annurev.physiol.67.031103.153004

[24] Orlowski, J. and Grinstein, S. (2004) Diversity of the mammalian sodium proton exchanger SLC9 gene family. Pflüegers Archives, 447, 549-565. doi:10.1007/s00424-003-1110-3

[25] Therien, A.G. and Blostein, R. (2000) Mechanisms of sodium pump regulation. American Physiologial Society, 279, 541-566.

[26] Inagaki, E., Kawamata, K. and Suzuki, Y. (2002) In vitro potassium transport in the mouse small intestine. Japanese Journal of Physiology, 52, 515-520. doi:10.2170/jjphysiol.52.515 